\title{
BULLYING HOMOFÓBICO E DESENGAJAMENTO MORAL: QUANDO A JUSTIFICATIVA MORAL E A CULPABILIZAÇÃO DIZEM "PRESENTE"
}

\author{
INTIMIDACIÓN HOMOFÓBICA Y DESCONEXIÓN MORAL:CUANDO LA \\ JUSTIFICACIÓN MORAL Y LA CULPABILIZACIÓN DICEN “PRESENTE”
}

HOMOPHOBIC BULLYING AND MORAL DISENGAGEMENT: WHEN MORAL JUSTIFICATION AND GUILTY SAY “PRESENT”

\author{
Carla Beatriz Pereira da SILVA ${ }^{1}$ \\ Wanderlei Abadio de OLIVEIRA ${ }^{2}$ \\ Jorge Luiz da SILVA ${ }^{3}$ \\ Marta Angélica Iossi SILVA ${ }^{4}$
}

RESUMO: O presente estudo buscou identificar aspectos do desengajamento moral relacionados ao bullying homofóbico vivenciado na infância e/ou adolescência de estudantes universitários. Por meio de uma pesquisa qualitativa foram entrevistados 14 universitários de uma cidade do interior do estado de São Paulo que se autodeclararam gays ou lésbicas. $\mathrm{O}$ grupo de participantes foi constituído por meio da técnica snowball sampling. Um roteiro com questões norteadoras explorou a percepção dos participantes sobre os mecanismos do desengajamento moral como motivadores para experiencias do bullying homofóbico sofridos durante o ensino fundamental e médio. Os dados da pesquisa foram analisados por meio da análise de conteúdo, modalidade temática. Os resultados obtidos nessa pesquisa apontaram que os agressores estavam desengajados moralmente e culpabilizam as vítimas para se sentirem melhor, justificando moralmente seus comportamentos. Este estudo aponta que intervenções antibullying deve considerar a disseminação de conteúdos sobre valores humanos, respeito à diversidade e a gravidade do comportamento agressivo de crianças e adolescentes.

PALAVRAS-CHAVE: Bullying homofóbico. Desengajamento moral. Escola.

RESUMEN: El presente estudio tenía como objetivo identificar aspectos de la separación moral relacionadas con el acoso homofóbico experimentado en la infancia y/o adolescencia

\footnotetext{
${ }^{1}$ Escola de Enfermagem de Ribeirão Preto (EERP-USP), Ribeirão Preto - SP - Brasil. Discente Programa de Pós-Graduação em Enfermagem Psiquiátrica. ORCID: https://orcid.org/0000-0001-9579-8315. E-mail: carla.beatriz.silva@usp.br

${ }^{2}$ Pontifícia Universidade Católica de Campinas (PUC-Campinas), Campinas - SP - Brasil. Docente Permanente do Programa de Pós-Graduação em Psicologia. Doutorado em Enfermagem em Saúde Pública (USP). ORCID: https://orcid.org/0000-0002-3146-8197.E-mail: wanderleio@usp.br

${ }^{3}$ Universidade de Franca (UNIFRAN), Franca - SP - Brasil. Docente Permanente no Programa de PósGraduação em Promoção de Saúde. Doutorado em Enfermagem em Saúde Pública (USP). ORCID: de https://orcid.org/0000-0002-3727-8490. E-mail: jorge.silva@unifran.edu.br

4 Escola de Enfermagem de Ribeirão Preto (EERP-USP), Ribeirão Preto - SP - Brasil. Docente Associada no Departamento de Enfermagem Materno-Infantil e Saúde Pública. Programa de Pós-Graduação Enfermagem em Saúde Pública. Doutorado em Enfermagem em Saúde Pública (USP). ORCID: https://orcid.org/0000-00029967-8158. E-mail: maiossi@eerp.usp.br
}

RIAEE - Revista Ibero-Americana de Estudos em Educação, Araraquara, v. 15, n. 4, p. 2066-2077, out./dez. 2020. e-ISSN: 1982-5587. DOI: https://doi.org/10.21723/riaee.v15i4.13898 
de los estudiantes universitarios. A través de una investigación cualitativa, 14 estudiantes universitarios de una ciudad en el interior del estado de Sao Paulo que se declararon gays o lesbianas fueron entrevistados. El grupo de participantes fue constituido por la técnica de muestreo de bolas de nieve. Un guión con preguntas orientativas exploró la percepción de los participantes de los mecanismos de separación moral como motivadores para las experiencias de acoso homofóbico sufridas durante la escuela primaria y secundaria. Los datos de investigación se analizaron a través del análisis de contenido, modalidad temática. Los resultados obtenidos en esta investigación indicaron que los agresores estaban moralmente desenganchados y culparon a las víctimas por sentirse mejor, justificando moralmente sus comportamientos. Este estudio señala que las intervenciones anti-bullying deben considerar la difusión de contenidos sobre los valores humanos, el respeto por la diversidad y la gravedad de la conducta agresiva en niños y adolescentes.

PALABRAS CLAVE: Acoso homofóbico. Desenganche moral. Escuela.

ABSTRACT: This study sought to identify aspects of moral disengagement related to homophobic bullying experienced in the childhood and/or adolescence of university students. Through qualitative research, 14 college students from a city in the interior of the state of São Paulo were interviewed who declared themselves gay or lesbian. The group of participants was constituted through the snowball sampling technique. A script with guiding questions explored participants' perception of the mechanisms of moral disengagement as motivators for homophobic bullying experiences suffered during elementary and high school. The research data was analyzed through content analysis, thematic modality. The results obtained in this research showed that aggressors were morally disengaged and blame victims for feeling better, morally justifying their behavior. This study points out that anti-bullying interventions should consider the dissemination of content about human values, respect for diversity and the seriousness of aggressive behavior of children and adolescents.

KEYWORDS: Homophobic bullying. Moral disengagement. School.

\section{Introdução}

O conceito de bullying homofóbico se refere a um tipo de violência sofrido por crianças e adolescentes em idade escolar e que se relaciona a provocações, discriminação, violência física e outras formas de agressão motivadas pela orientação sexual dos estudantes (ELIPE; MUNOZ; DEL REY, 2018). Trata-se de um comportamento violento repetitivo, executado por um ou mais estudantes contra seus pares, particularizado pelo desequilíbrio de poder simbólico baseado em valores associados ao heterossexismo, sexismo e homofobia, na medida em que as agressões se voltam para aqueles colegas que quebram padrões normativos de orientação sexual e identidade de gênero ou qualquer estudante percebido como tal (RODRIGUES; GRAVE; OLIVEIRA; NOGUEIRA, 2016). 
Embora o bullying escolar venha sendo extensivamente estudado, a experiência de estudantes homossexuais, gays e lésbicas, pode ser considerada um fenômeno específico. A literatura científica tem demonstrado que estudantes em diferentes níveis de escolarização e identificados como não-heterossexuais apresentam maior possibilidade ou risco para a vitimização por bullying (KOSCIW; PIZMONY-LEVY, 2016; ESPELAGE; HONG; MERRIN; DAVIS; ROSE; LITTLE, 2018). Além disso, esse tipo de experiência impacta na saúde mental e na maneira como esses sujeitos internalizam o processo ensino-aprendizagem, bem como as experiências institucionais de escolarização/formação em diferentes momentos do ciclo vital, não se restringindo à infância ou adolescência (RODRIGUES et al., 2016).

No Brasil essa abordagem ainda é recente, pois a maioria das pesquisas possui foco no diagnóstico ou caracterização da ocorrência do bullying em suas manifestações gerais. Com relação ao bullying homofóbico, um estudo realizado com 638 estudantes universitários brasileiros evidenciou que a vitimização verbal e situações de isolamento social foram as mais referidas pelos participantes, sendo associados quadros de adoecimento psíquico como consequência desse tipo de experiência (ALBUQUERQUE; WILLIAMS, 2015). Outro estudo visou documentar o bullying homofóbico verbal/psicológico e modelar a relação entre essa experiência e a homofobia internalizada e autoestima entre 300 jovens canadenses de minorias sexuais (BLAIS; GERVAIS; HÉBERT, 2014). Segundo os resultados, $60,7 \%$ da amostra referiram pelo menos uma forma de bullying homofóbico verbal/psicológico, fato parcialmente associado a problemas de autoestima e homofobia internalizada (BLAIS; GERVAIS; HÉBERT, 2014).

Outras pesquisas identificaram que a orientação sexual é um dos motivos ou causas atribuídas para a vitimização por bullying nas escolas (OLIVEIRA; SILVA; QUERINO; SILVA, 2016; OLIVEIRA; SILVA; MELLO; PORTO; YOSHINAGA; MALTA, 2015). Da mesma forma que investigações documentaram associações significativas entre bullying e desengajamento moral (CARAVITA; SIJTSEMA; RAMBARAN; GINI, 2014; THORNBERG; JUNGERT, 2014). O desengajamento moral é um processo sociocognitivo, um constructo baseado na Teoria Social Cognitiva (BANDURA, 2008) e é utilizado para explicar e mostrar como as pessoas podem encontrar justificativas para cometer atos antissociais sem se sentirem culpadas ou censuradas (AZZI, 2011; BANDURA, 2008). Esse constructo é composto por oito mecanismos, quais sejam: justificativa moral, comparação vantajosa, linguagem eufemística, distorção de consequências, desumanização, culpabilização da vítima, deslocamento de responsabilidade e difusão de responsabilidade (AZZI, 2011; BANDURA, 2008).

RIAEE - Revista Ibero-Americana de Estudos em Educação, Araraquara, v. 15, n. 4, p. 2066-2077, out./dez. 2020. e-ISSN: 1982-5587. 
Segundo Azzi (2011) um conjunto de fenômenos sociais podem ser discutidos a partir do referencial teórico do desengajamento moral, como, por exemplo, a violência policial, política e doméstica, as situações de abuso sexual, entre outros, no nosso entendimento, como a homofobia, oferecendo, assim, uma possibilidade de análise para ações prejudiciais exercidas nas relações e cotidiano de diferentes grupos sociais. Outrossim, estudos capazes de considerar esses dois constructos - bullying homofóbico e desengajamento moral - se fazem necessários para compreender os fatores que tornam as vítimas vulneráveis e oferecer visibilidade para esse grupo social, além de se oferecer subsídios científicos para a abordagem desta problemática social.

Assim, este estudo objetivou identificar aspectos de desengajamento moral relacionados a justificativa moral e a culpabilização das vítimas na ocorrência do bullying homofóbico vivenciado na infância ou adolescência por estudantes universitários.

\section{Materiais e Métodos}

Trata-se de um estudo qualitativo com enfoque descritivo e exploratório, que buscou aprofundar a descrição do bullying homofóbico e como ele é significado por vítimas com relação a justificativa moral e culpabilização, mecanismos de desengajamento moral.

O grupo de participantes foi constituído por meio da técnica snowball sampling (bola de neve) que se inicia com um participante que vai sucessivamente indicando novos sujeitos para participação do estudo (VON DER FEHR; SOLBERG; BRUUN, 2018). O número final de participantes foi definido por meio da estratégia de saturação. O cenário do estudo foi uma universidade pública do interior do estado de São Paulo, selecionada por conveniência.

Os critérios de inclusão dos sujeitos foram: ser aluno regularmente matriculado no ensino superior na instituição selecionada para coleta de dados; autodeclarar-se homossexual ou lésbica com relatos de violências ou agressões sofridas na infância ou na adolescência no contexto escolar. Não houve delimitação de idade ou faixa etária para inclusão no estudo.

As entrevistas foram orientadas por um roteiro que explorou a percepção dos participantes sobre os mecanismos de desengajamento moral desenvolvido por Bandura (2008) particularmente os mecanismos justificativa moral e culpabilização da vítima como motivadores possíveis para experiências de bullying homofóbico sofridas nos Ensinos Fundamental e/ou Médio. As entrevistas foram gravadas em um smartphone por meio de um aplicativo de gravação de áudio MP3 e posteriormente transcritas pela pesquisadora responsável. Os entrevistados foram identificados por pseudônimos (Madonna, Beyoncé, 
Joana Darc, Iza, Mariele Franco, Frida Kahlo, Amélia Earhart, Florence Nightingale, Malala Yousafzai, Marsha Jhonson, Marta Silva, Édith Piaf, Tarsila do Amaral e Ísis) para que fossem preservadas a identidade dos sujeitos e sigilo das informações.

Participaram do estudo 14 alunos de graduação, sendo 6 graduandos do sexo biológico masculino, autodeclarados gays, e 8 graduandas do sexo biológico feminino que se autodeclararam lésbicas. Os participantes tinham idades entre 18 a 28 anos, estavam regularmente matriculados no ensino superior e relataram situações de violência ou agressões sofridas durante o ensino fundamental e/ou médio

Para análise dos dados utilizou-se o método de análise de conteúdo, modalidade temática (GOMES, 2009; BARDIN, 2011). A trajetória analítico-interpretativa percorreu três fases fundamentais: 1) pré-análise (leitura flutuante do material obtido), 2) exploração do material (com categorização e organização por temas, tendo como referência teórica os mecanismos de desengajamento moral) e 3) tratamento dos resultados (inferência e interpretação dos dados) (BARDIN, 2011).

Segundo Gomes (2009) a análise e interpretação de dados qualitativos refere-se a finalização do trabalho investigativo, articulando o conteúdo de falas coletadas aos objetivos da investigação e a fundamentação teórica. Esse foi o exercício realizado nesse trabalho.

O projeto de pesquisa foi analisado e aprovado pelo Comitê de Ética em Pesquisa (CEP) da Escola de Enfermagem de Ribeirão Preto/USP, protocolo CAAE: 02882618.0.0000.5393, Ofício de Aprovação CEP-EERP/USP n 047/2019, respeitando as exigências éticas e recomendações da Resolução 466/2012 e Resolução 510/2016 do Conselho Nacional de Saúde.

\section{Resultados e Discussões}

Identificou-se situações de desengajamento moral em relação ao bullying homofóbico vivenciado na infância e/ou adolescência, sobretudo aquelas relacionadas à justificativa moral e culpabilização das vítimas, compreendendo os mecanismos utilizados para explicar as agressões sofridas. Os estudantes entrevistados relataram que sofreram bullying homofóbico dentro e fora das escolas, sendo que se destacaram as agressões sofridas no contexto familiar e pontos com diversos tipos de situações de agressões verbais, físicas e psicológicas até denominando-as tais ações como "tortura psicológica". Dentre os 14 entrevistados, três relataram que sofreram agressões físicas, tipo de violência não predominante nesse estudo. 
Tema 1 - Justificativa Moral - “...Porque querendo ou não é uma coisa instituída na sociedade..."

$\mathrm{Na}$ teoria social cognitiva, o pensamento moral é um processo em que regras e padrões são usados para o julgamento da conduta ou comportamento (AZZI, 2011). No âmbito do desengajamento moral a justificativa moral se institui a partir da reconstrução cognitiva que representa a transgressão à serviço de propostas morais valorizadas (IGLESIAS, 2008).

Neste sentido, por meio de um processo cognitivo, busca-se encontrar justificativas ou explicações para determinado acontecimento que deve ser mensurável e controlado, além de permitir a si mesmo praticar atos desumanos sem sofrer a angústia da autocondenação. Isso só é possível por meio do uso do mecanismo de justificativa moral, como relataram os participantes desse estudo:

Meus colegas, no caso quem me xingava? Só do fato de existir mesmo e tá
ali sendo diferente deles ... esse eu acho que era o maior motivo deles
sempre, sabe?... Vendo num ponto de vista agora, eu acho que é um contexto
que eles eram colocados desde criança, sabe? Porque, querendo ou não, é
uma coisa que é instituída na sociedade né, o machismo e tudo mais, então,
por exemplo, sempre era um grupinho, né, nunca um individual, então
sempre piadas homofóbicas. Eu acho que isso cada vez aumentava mais
sabe, a vontade deles xingarem alguém pra aparecer, um pouco de
maturidade também, de não saber se comportar em sociedade (BEYONCÉ).

Geralmente eles tinham uma visão muito estereotipada sobre o gay, homossexual. Essa imagem negativa que trazem sobre a homossexualidade que até nós mesmos carregamos por boa parte da nossa vida antes da gente se assumir [...] então eles justificavam falando que gay tem que apanhar mesmo, que é, fica fazendo coisa ruim (JOANA DARC).

Deste modo, comportamentos violentos e intolerantes encontram em propósitos morais uma forma de torná-los socialmente aceitáveis. Segundo França e Amorim (2017) princípios religiosos, imperativos nacionalistas e ideologias têm sido usados como meios para justificar condutas repreensíveis e destrutivas, sobretudo com relação às práticas machistas ou relativas ao patriarcado, enquanto um modo de organizar a sociedade, suas ideias e comportamentos.

Esta forma de desengajamento acontece porque antes da decisão de se envolver em um comportamento, as pessoas decidem e permitem ações antissociais ou prejudicais a outros, após terem justificado as ações em um fundamento moral, que foi construído a partir da organização do pensamento do sujeito (BANDURA, 2008). Como no caso da homossexualidade há uma fuga da norma ou do padrão esperado, muitas pessoas acabam compactuando ou sendo negligentes com os agressores, pois compactuam em alguma medida 
com as agressões ou violências testemunhadas, como frisado pelas participantes desse trabalho:

Quando eu estava no ensino fundamental, as coisas eram mais diferentes do que hoje, então, era algo que era imposto por todos, até pelos professores, eles não entravam no meio caso alguém me chamasse de "gordo viado", "viadinho", ficava por isso mesmo, não tinha intervenção do professor ali (MALALA YOUSAFZAY).

Olha, eu pensei muito, muitas vezes, porque pra mim eu nunca entendi. Muitas pessoas falavam que não é da época deles, só que já foi comprovado de todas as formas possiveis que não existe esse lance de que não é da época deles porque isso sempre existiu só que nunca teve tanta representatividade [...] ai parece que deu um choque na população, então eu acredito que foi por conta disso, por isso das pessoas acharem que é errado (FLORENCE NIGHTINGALE).

Especificamente, a fala "por isso das pessoas acharem que é errado" mobiliza um conjunto de comportamentos psicossociais que permite às pessoas não avaliarem como negativos os seus comportamentos, bem como não considerarem os efeitos nocivos por suas condutas transgressoras, desumanas e antissociais. Embora no caso do bullying, sabe-se que há uma intenção de causar dor ou sofrimento às vítimas. Esse é um dos critérios para sua definição como fenômeno e ocorrência, sendo mensurado pela capacidade dos agressores de compreenderem, racionalmente, que o ato empreendido contra o ou os colegas é errado ou deixa o outro entristecido/magoado etc. (OLWEUS, 2013).

Esses relatos apresentados demonstram ainda que os alunos, mesmo em sala de aula, nem sempre podem contar com os professores para auxiliá-los em situações de bullying homofóbico vivenciadas, pois os professores frequentemente não se envolvem ou denunciam este tipo de vitimização, podendo, até mesmo, reforçarem pela negligência ou cumplicidade a vitimização homofóbica (KOSCIW; PIZMONY-LEVY, 2016). Isso ocorre, muitas vezes, pela esperança de corrigir aquilo que está fora da norma e não corresponde ao padrão esperado ou aos estereótipos de homem e mulher.

Observa-se nas falas dos sujeitos que há uma construção cognitiva que representa a transgressão para atender justificativas e propostas morais valorizadas em um tempo histórico e sociocultural, como assinala uma das participantes:

Pelo contexto eu acho machista. Porque é algo sociocultural. Principalmente por conta da cidade aonde eu vivo ela é pequena e tem muito contexto de que o homem não pode dançar, o homem tem que jogar futebol, o homem não pode ter amigas meninas, o homem tem que andar só com meninos (ÉDITH PIAF).

RIAEE - Revista Ibero-Americana de Estudos em Educação, Araraquara, v. 15, n. 4, p. 2066-2077, out./dez. 2020. e-ISSN: $1982-5587$. 
Tema 2 - Culpabilização - "Eu me sentia culpado porque é como se fosse uma coisa que eu pudesse mudar"

As vítimas, muitas vezes, acabam assumindo a culpa pelas agressões que sofrem. Embora esse seja um movimento recorrente, o desengajamento moral é dos agressores, mas as vítimas tendem a internalizar esse modo de pensar ou avaliar as situações. Ao mesmo tempo, a atribuição de culpabilização se define quando as pessoas vêm a si mesmas como vítimas sem culpa ou a ver suas vítimas como culpadas e merecedoras de seu prejuízo (IGLESIAS, 2008). Uma das participantes assinalou esse aspecto fortemente:

Eu me sentia culpada por ser lésbica, me sentia culpada por ter me apaixonada por uma menina, eu me sinto culpada até hoje na verdade, porque acho que fui eu que causei tudo isso, sabe?[...] porquê que tinham me expulsado de casa, sempre, ah, é mal comportamento, má influência, ninguém tentava entender o que eu estava passando e até eu comecei a me culpar de ser lésbica, eu comecei a me culpar por gostar de menina e eu comecei a me repreender nesse sentido, de pensar que isso era errado, que isso não era de Deus (FLORENCE NIGHTINGALE).

Nota-se que ao relatar ou analisar a situação, a participante demonstra ter internalizado uma culpa que não é sua. Da mesma forma podemos pensar que para o agressor está tudo bem, pois a culpa realmente é da vítima - essa é a dinâmica do desengajamento moral. Observa-se também nesse fragmento uma clara atribuição da culpa ao sujeito homossexual. Atendendo ao conceito de desengajamento moral por meio do mecanismo de atribuição da culpa engenha-se uma visão das vítimas como culpadas e merecedoras das ações de homofobia. Isso é um processo: o agressor age com violência porque o outro é homossexual ou lésbica, e as vítimas passam a carregar essa culpa como suas.

Assim sendo, especificamente nas situações de bullying são exatamente os agressores, aqueles que justificam sua conduta para não se sentirem culpados. Auto justificam seu comportamento agressivo para manter uma boa imagem condizente com os padrões formados por conteúdos morais ou não (TOGNETTA; AVILÉS; ROSÁRIO; ALONSO, 2015).

A transferência da culpa é um mecanismo de desengajamento moral utilizado para convencer a outrem que o sujeito assumidamente homossexual é culpado, por exemplo de comportamentos que ferem a heteronormatividade imposta na sociedade.

Percebe-se que no processo de desengajamento o sujeito que transgride se encontra livre de autocensura e culpa (BANDURA, 2008) o que frente a homofobia serviria como uma resposta aos padrões instituídos. Quando temos o encontro de um status social dessa natureza 
e processos cognitivos que o mantêm, a perspectiva é de aumento das situações de violência e perpetração da insegurança daqueles que são assinaladamente diferentes.

Assim sendo, fica claro que as questões de gênero e orientação sexual na infância e adolescência estabelecem a violência no cotidiano daqueles que desviam da norma heterossexual, pois envolve relações hierárquicas e de poder, voltando-se majoritariamente àqueles que transgridem a lógica binária (feminino/masculino) materializando-se por meio de vitimização homofóbica, isolamentos sociais e discriminação (TOOMEY; MCGUIRE; RUSSELL, 2012).

Portanto, é possível, a partir do conjunto de dados, perceber que desengajamento moral relacionado à justificativa moral e à culpabilização na ocorrência do bullying homofóbico fazem com que os agressores sejam caracterizados como "desengajados moralmente". Eles culpabilizam as vítimas para se sentirem melhor e justificar moralmente suas atitudes, como se crianças e adolescentes homossexuais não sejam de respeito, dignidade e de uma convivência social plena e saudável. Além disso, as vítimas internalizam esse modo de compreender as violências sofridas e como as significam, mesmo em outro momento do ciclo vital.

\section{Considerações finais}

O presente estudo analisou as experiências de desengajamento moral relacionado ao bullying homofóbico vivenciado por estudantes universitários, gays e lésbicas. A vivência dos estudantes, tanto no ambiente escolar, como fora deste, foi pautada por processos de preconceito, discriminação e a exclusão devido sua orientação sexual. Os participantes ainda relataram que carregam sentimento de culpa (processo de internalização) até os dias atuais, algo que impacta diretamente na autoaceitação e sofrimento constante.

Ressalta-se que o bullying homofóbico promove o isolamento social, vulnerabiliza os sujeitos e reduz seus direitos fundamentais. Diante deste contexto, reitera-se a importância da sociedade e de suas instituições sociais, a exemplo da escola, serem um espaço de real construção da cidadania e (con)vivência com a diversidade sexual. Assim, a partir dos dados apresentados, sugere-se que intervenções antibullying considerarem a disseminação de conteúdos sobre valores humanos, respeito à diversidade e a gravidade do comportamento agressivo entre os estudantes. 
Em tempos atuais, onde as relações humanas deveriam pautar a justiça e a igualdade, vemos a discriminação, a resistência e ação da violência simbólica ou explicita dar contorno a vida. Sejamos lutadores, digamos também...presente!

AGRADECIMENTOS: Programa Unificado de Bolsas de Estudo (PUB-USP) da Universidade de São Paulo - Bolsa Iniciação Científica. Apoio do Conselho Nacional de Desenvolvimento Científico e Tecnológico /CNPq - Bolsa Produtividade em Pesquisa Processo: 305469/2019-3.

\section{REFERÊNCIAS}

ALBUQUERQUE, P. P.; WILLIAMS, L. C. A. Homofobia na escola: relatos de universitários sobre as piores experiências. Temas psicol., v. 23, n. 3, p. 663-676, 2015. Disponível em: http://pepsic.bvsalud.org/pdf/tp/v23n3/v23n3a11.pdf. Acesso em: 15 jun. 2020.

AZZI, R. G. Desengajamento moral na perspectiva da teoria social cognitiva. Psicol. cienc. prof., v. 31, n. 2, p. 208-219, 2011. Disponível em:

https://www.scielo.br/scielo.php?script=sci_arttext\&pid=S14148932011000200002\&lng=pt\& tlng=pt. Acesso em: 15 jun. 2020.

BANDURA, A.; AZZI, R. G.; POLYDORO, S. A. J. (Orgs.). Teoria social cognitiva, conceitos básicos. Porto Alegre: Artmed, 2008.

BARDIN, L. Análise de conteúdo. São Paulo: Edições 70, 2011.

BLAIS, M.; GERVAIS, J.; HÉBERT, M. Internalized homophobia as a partial mediator between homophobic bullying and self-esteem among youths of sexual minorities in Quebec (Canada). Ciênc. saúde coletiva, v. 19, n. 3, p. 727-735, 2014. Disponível em:

https://www.ncbi.nlm.nih.gov/pmc/articles/PMC5108649/. Acesso em: 12 maio 2019.

CARAVITA, S. C. S.; SIJTSEMA, J. J.; RAMBARAN, J. A.; GINI, G. Peer influences on moral disengagement in late childhoodand early adolescence. Journal of youth and adolescence, v. 43, n. 2, p. 193-207, 2014. Disponível em:

https://publicatt.unicatt.it/handle/10807/64419. Acesso em: 11 ago. 2019.

ELIPE, P.; MUNOZ, M. D.; DEL REY, R. Homophobic bullying and cyberbullying: study of a silenced problem. Journal of Homosexuality, v. 65, n. 5, p. 672-686, 2018. Disponível em: https://www.tandfonline.com/doi/full/10.1080/00918369.2017.1333809. Acesso em: 15 jun. 2020.

ESPELAGE, D. L.; HONG, J. S., MERRIN; G. J.; DAVIS, J. P.; ROSE, C. A.; LITTLE, T. D. A longitudinal examination of homophobic name-calling in middle school: bullying, traditional masculinity, and sexual harassment as predictors. Psychology of Violence, v. 8, n. 
1, p. 57-66, 2018. Disponível em: https://psycnet.apa.org/fulltext/2018-40534-001.html. Acesso em: 11 ago. 2019.

FRANÇA, G. K. C. S.; AMORIM, W. L. Algumas práticas e discursos machistas sob a ótica do desengajamento moral de Albert Bandura. Revista Humus, v. 7, n. 19, p. 141-153, 2017. Disponível em:

http://www.periodicoseletronicos.ufma.br/index.php/revistahumus/article/view/7007. Acesso em: 15 jun. 2020.

GOMES, R. Análise e interpretação de dados de pesquisa qualitativa. In: MINAYO, M. C. S. (Org.). Pesquisa social: teoria, método e criatividade. 28. ed. Petrópolis: Editora Vozes, 2009.

IGLESIAS, F. Desengajamento moral. In: BANDURA, A.; AZZI, R. G.; POLYDORO, S. A. J. (Org.). Teoria social cognitiva: conceitos básicos. Porto Alegre: Artes Médicas 2008. p. 165-176.

KOSCIW, J. G.; PIZMONY-LEVY, O. International perspectives on homophobic and transphobic bullying in schools. Journal of LGBT Youth, v. 13, n. 1-2, p. 1-5, 2016. Disponível em: https://www.tandfonline.com/doi/full/10.1080/19361653.2015.1101730. Acesso em: 12 maio 2019.

OLIVEIRA, W. A.; SILVA, J. L.; QUERINO, R. A; SILVA, M. A. I. Experiences and perceptions of discrimination related to bullying among Brazilian students. Maltrattamento e abuso all'infanzia, v. 18, n. 1, p. 29-57, 2016. Disponível em:

https://repositorio.usp.br/item/002782942. Acesso em: 11 ago. de 2019.

OLIVEIRA, W. A.; SILVA, M. A. I.; MELLO, F. C. M.; PORTO, D. L.; YOSHINAGA, A. C. M; MALTA, D. C. The causes of bullying: results from the National Survey of School Health (PeNSE). Rev. Latino-Am. Enfermagem, v. 23, n. 2, p. 275-282, 2015. Disponível em: https://www.scielo.br/scielo.php?script=sci_arttext\&pid=S0104$11692015000200013 \&$ tlng=en. Acesso em: 15 jun. de 2020.

OLWEUS, D. School bullying: development and some important challenges, Annu Rev Clin Psychol, v. 9, p. 751-780, 2013. Disponível em:

https://www.annualreviews.org/doi/10.1146/annurev-clinpsy-050212-185516. Acesso em: 11 ago. 2019.

RODRIGUES, L.; GRAVE, R.; OLIVEIRA, J. M.; NOGUEIRA, C. Study on homophobic bullying in Portugal using Multiple Correspondence Analysis (MCA). Revista

Latinoamericana de Psicologia, v. 48, n. 3, p. 191-200, 2016. Disponível em: https://www.sciencedirect.com/science/article/pii/S0120053416300036?via\%3Dihub. Acesso em: 15 jun. 2020.

THORNBERG, R.; JUNGERT, T. School Bullying and the Mechanisms of Moral Disengagement. Aggressive Behavior, v. 40, n. 2, p. 99-108, 2014. Disponível em: https://onlinelibrary.wiley.com/doi/full/10.1002/ab.21509. Acesso em: 11 ago. 2019.

TOGNETTA, L. R. P.; AVILÉS, J. M.; ROSÁRIO, P.; ALONSO, N. Desengajamentos morais, autoeficácia e bullying: a trama da convivência. Revista de Estudios e Investigación 
en Psicología y Educación, v .2, n. 1, p. 30-34, 2015. Disponível em:

https://revistas.udc.es/index.php/reipe/article/view/714. Acesso em: 11 ago. 2019.

TOOMEY, R. B.; MCGUIRE, J. K.; RUSSELL, S. T. Heteronormativity, school climates, and perceived safety for gender nonconforming peers. Journal of Adolescence, v. 35, n. 1, p. 187-196, 2012. Disponível em:

https://arizona.pure.elsevier.com/en/publications/heteronormativity-school-climates-andperceived-safety-for-gender. Acesso em: 11 jul. 2019.

VON DER FEHR, A.; SOLBERG, J.; BRUUN, J. Validation of networks derived from snowball sampling of municipal science education actors. International Journal of Research \& Method in Education, v. 41, n. 1, p. 38-52, 2018. Disponível em: https://www.tandfonline.com/doi/full/10.1080/1743727X.2016.1192117. Acesso em: 15 jun. 2020.

\section{Como referenciar este artigo}

SILVA, C. B. P; OLIVEIRA, W. A.; SILVA, M. A. I; SILVA, J. L. Bullying homofóbico e desengajamento moral: quando a justificativa moral e a culpabilização dizem "presente". Revista Ibero-Americana de Estudos em Educação, Araraquara, v. 15, n. 4, p. 2066-2077, out./dez. 2020. e-ISSN: 1982-5587. DOI: https://doi.org/10.21723/riaee.v15i4.13898

Submetido em: 05/02/2020

Revisões requeridas em: $25 / 04 / 2020$

Aprovado em: 30/06/2020

Publicado em: 30/08/2020 